\title{
The Experiences of Some Early and Elementary Education Living-Learning Community Participants
}

\author{
Tobin Richardson ${ }^{1, *}$, James Stroud $^{2}$ \\ ${ }^{1}$ Department of Educational Studies, Ball State University, Muncie, IN, USA \\ ${ }^{2}$ Department of Elementary Education, Ball State University, Muncie, IN, USA \\ *Corresponding author: tmrichardso2@bsu.edu
}

Received September 12, 2014; Revised September 20, 2014; Accepted September 26, 2014

\begin{abstract}
Many factors may influence how a student experiences his or her residence community involvement. Ball State University, an institution with a history of innovative and effective housing programs, recently implemented a living-learning community comprised of students declaring majors within their Department of Elementary Education. A total of 15 participants who had resided within this living-learning community for a minimum of one academic-year were interviewed. Interviews focused on students overall experience within the Early and Elementary Education Living-Learning Community. Common themes emerging from the semi-structured interviews included participants feeling connected and comfortable quickly within their college transition, social benefit including the development and maintenance of long-term friendships, and academic benefit including better course performance and more commitment towards the field of study.
\end{abstract}

Keywords: living-learning community, residence life, college transition, elementary education

Cite This Article: Tobin Richardson, and James Stroud, "The Experiences of Some Early and Elementary Education Living-Learning Community Participants.” American Journal of Educational Research, vol. 2, no. 10 (2014): 856-861. doi: 10.12691/education-2-10-3.

\section{Introduction}

Colleges and universities continue to employ a variety of educational initiatives designed to promote student learning and engagement that happens outside of the classroom (Garrett \& Zabriskie, 2004). One common approach implemented in effort to further foster student satisfaction and success is the creation of living-learning communities (LLCs) within structures of housing and residence life. LLCs are formal living arrangements, developed within residence halls that are typically organized to contain students who identify their academic pursuits or interests in a certain way. These units can take a variety of forms, but often focus on grouping students within certain majors, educational interests, or based on a variety of other academic or even non-academic characteristics such as those within an honors program, who commit to a substance-free lifestyle, or who identify internationally (Stassen, 2003). LLCs aim to connect students sharing a certain commonality outside of the classroom in order to cultivate a more conducive and immersive learning environment, and are argued by many to ultimately increase students' overall level of scholarship and educational satisfaction. In addition to improving educational initiatives, LLCs are often thought to provide a level of structure and safety for students transitioning to college, as the structure allows for students to get to know their residential peers on a more personal level, often giving the opportunity to see the same students in a variety of contexts. Although research supports the development of LLCs within colleges and universities, there are many factors that may impact the overall experience of a specific student or group of students residing within an LLC. These factors may include the specific nature and structure of the program, the variable used to group students, or characteristics related to the students' themselves, such as the level of desire to build relationships with those with similar academic interests.

Ball State University, the institution used within this study, is a mid-sized public institution located in the Midwestern United States. This university has a history of organizing and utilizing LLCs with exceptional intention, beyond what is typically characteristic of other institutions similar in size and assembly. There are many illustrations of the universities commitment to creating and maintaining high quality LLCs such as the number of LLCs on campus, a close faculty and staff involvement with residence life programs, and live in academic peer mentors who provide additional guidance to students within LLC programs.

At Ball State University LLC programs in some form have been in existence since 1998 when a first-year student program called "Freshmen Connections" was implemented. This program included a communal learning experience aimed to cultivate out-of-the-classroom engagement similar to LLCs. In 2004, students began being housed more strategically by major or interest area (e.g. nursing majors, substance-free students, international students) which evolved into what is now a highly 
sophisticated LLC assembly. The program currently includes over 10 major LLCs revolving around various academic and social variables, and the majority of freshman students are housed within one of the universities LLCs. Some of the largest LLCs in terms of population of students within the university are within the Honors College and those LLCs grouping the nursing and business majors. As demonstrated through data obtained through the LLC Academic Outcomes Report during a two-year period from 2011 to 2013, freshman housed within LLCs on the Ball State University campus had better grade point averages, more credit hours earned, and were more likely to enroll in the spring semester as compared to their non-LLC counterparts.

Table 1. LLC Academics Outcome Report (2011-2013)

\begin{tabular}{|c|c|c|c|c|}
\hline & $\begin{array}{c}\text { Average Fall } \\
\text { GPA }\end{array}$ & $\begin{array}{c}\text { Average Fall Earned Credit } \\
\text { Hours }\end{array}$ & $\begin{array}{c}\text { Average Spring Earned } \\
\text { Credit Hours }\end{array}$ & $\begin{array}{c}\text { Percentage of Students on Acad. } \\
\text { Probation after Fall }\end{array}$ \\
\hline LLC Participants 2013 & 3.0711 & 14.61 & 13.42 & 10.91 \\
\hline $\begin{array}{c}\text { On-campus Non-LLC } \\
2013\end{array}$ & 2.77 & 13.7 & 12.6 & 18 \\
\hline Off-campus 2013 & 2.707 & 13 & 13.97 & 13.9 \\
\hline LLC Participants 2012 & 2.8851 & 13.94 & 12.5 & 18 \\
\hline $\begin{array}{c}\text { On-campus Non-LLC } \\
\text { 2012 }\end{array}$ & 2.673 & 12.9 & 13.89 & 16 \\
\hline Off-campus 2012 & 2.729 & 12.9 & 13.4 & 15.72 \\
\hline LLC Participants 2011 & 2.8548 & 13.91 & 13.8 & 16 \\
\hline $\begin{array}{c}\text { On-campus Non-LLC } \\
\text { 2011 }\end{array}$ & 2.75 & 13.5 & 12.7 & 20 \\
\hline Off-campus 2011 & 2.701 & State & 13 \\
\hline
\end{tabular}

LLCs like those developed by Ball State University support a growing trend in higher education to engross students in their educational pursuits outside of the classroom. Research repeatedly suggests engagement facilitated through immersive programs such as LLCs is a major factor associated with student retention, persistence, and success (Garrett \& Zabriskie, 2004; Rohli \& Rogge, 2012). To better understand the positive effect LLCs have on those who participate, it is important to acknowledge how this structure affects participants academically. As demonstrated on a campus level through the Ball State University Academic Outcomes Report, students residing within LLCs nationwide consistently perform at higher levels academically compared to their non-LLC counterparts. In addition, these students tend to complete more credit hours per semester as well as earn higher grade point averages overall (Stassen, 2003). In addition to academic advantages, students residing with LLC's often report a higher level of satisfaction within this living arrangement as compared to randomized housing assignments, especially when faculty and residence life staff members have direct and intentional involvement with the program (Frazier \& Eighmy, 2012). This is likely the case as there is an increased commonality among themselves and their housing peers, allowing for more comfort within the social environment. For example, a significant study by Shushok \& Sriram (2009) explored the effect of a partnership between academic affairs and student affairs by tracking the effects of a newly formed LLC on those who had declared majors within the fields of notoriously high levels of study attrition. The researchers split beginning students majoring in computer science and engineering, assigning some to an LLC, while others were placed randomly throughout the university housing system. The study found that those students who were part of the LLC elected to meet with their faculty members more often, met and worked with their peers more effectively, and were overall more satisfied with their academic pursuits. In other words, the LLC proved highly successful in terms of encouraging students to develop and maintain behaviors associated with persistence and success.
Although LLCs can be arranged in a variety of ways and may group students by several factors, a popular method for structuring LLCs is by area of study or major academic focus (Rohli \& Rogge, 2012). Major-specific LLCs often allow students to take the majority of the coursework with those who also reside within their residence hall, as is the case with the LLC examined within this study. This is important as social involvements are often imperative to the fulfilment of beginning university students, and can also be affected dramatically by the structure of the living environment and those who are surrounded by others with similar interests or ambitions may have an easier time connecting socially (Johnson \& Romanoff, 1999). To demonstrate this point, it is especially compelling to look at the social trends among those who enter college with unique barriers. It has been found that the transition to the college experience is reported much easier for those first-generation college students who are part of a LLC, in part because of the social support of those within their living area (Inkelas, Daver, Vogt, \& Leonard, 2007). Similarly, Henderickson, VanderBusar, Rodgers, \& Scheidecker (2013) found that those with intellectual disabilities fair better when placed within a LLC for a variety of reasons. Additional research by Freid (2009) found that those who were housed in a residential environment associated with those within their academic program were more likely to partake in university and community engagement. These findings all indicate that LLCs increase social connectedness and responsibility in some way for the majority of students residing within them.

Due in part to the success of LLCs programs both at Ball State University and national-wide, in 2011 the Department of Elementary Education along with the assistance from staff members within the Office of Housing and Residence Life implemented a LLC program specific to students within their majors. The Department of Elementary Education comprises programs in the fields of both elementary education and early childhood education at the undergraduate level. The programs within the Department of Elementary Education, as is often the similar among similar programs focusing on training in 
childhood education, have a history of being primarily comprised of female students. As Ball State University LLC students are housed in different dormitory floors based on gender, and because of the minimal number of men within the major, the male floor of the Elementary Education LLC has typically been located on a floor within the respective dormitory approximately half the size of the other floors, creating a unique living atmosphere for those students residing within it.

While examination of student success outcomes overwhelming indicate that all students fair better in residential units in which they are part of a LLC, some important gender considerations indicate that men and women often experience living-learning and other residential environments in different ways. Often these differences relate to the specific aspect of a LLC that provides the most benefit. Research by Yongyi, Arboleda, Shelley, \& Whalen (2004) found that those women who are most successful academically within their collegiate pursuits prefer to spend more time on studying as compared with socializing with those within their residence hall, regardless of commonalities between themselves and other residents. While this commitment to academics may prove beneficial educationally, it often times could lead to these women being viewed adversely by others within their housing unit. This demonstrates that women may be judged more harshly within residence halls if they do not attempt to immerse themselves fully in social activities. This may go more unnoticed in residence halls in which students are less familiar with their floormates. A similar study conducted by Szelényi, Denson \& Inkelas (2013) showed that women studying in traditionally male fields such as those with the STEM disciplines were most benefited by LLCs in which were coeducational in nature and in which career and academic conversations took place between all participants. This finding could support previous research which indicates that both genders, but especially women, are critical of those within their communities in which little interaction occurs, and that facilitating communication between participants improves both social and academic outcomes.

Men within LLCs may experience a different type of social influence, as their masculinity is often center to their identify development especially during the early collegiate years (Foste, Edwards, \& Davis, 2012). As men within collegiate settings may have more difficulty in feeling at ease in showing their true-self, LLCs may provide an opportunity for further genuine connection in part because of the multiple forms of contact between the classroom and residence hall. Jessup-Anger, Johnson, \& Wawrzynski (2012) found that men residing within LLCs may be provided with a better opportunity to further reject rigid social-roles that hinder healthy and comfortable identify development and genuine relationship building. In other words, these men may feel less pressured to behave in ways perceived as stereotypically masculine if they relate with others within their living-arrangement on a more personal level. This finding could have further implications for men in their future, as the amount of time men chose to live on their own or with friends after childhood and before marriage has a positive impact on their overall rejection of stereotypical gender norms through the lifetime (Pitt \& Borland, 2008).

\section{Methods}

Participants were recruited for this study through a list provided by the Office of Housing and Residence Life. This list indicated students who were part of the Early and Elementary Education LLC during the previous two-year period. Students were initially e-mailed explaining the nature of the study and asking for their participation. At the development and interview phases of this study, no consideration was given to gender of participant. Rather, authors were only looking to obtain data regarding residents' experiences within the Early and Elementary Education LLC. The initial e-mail indicated that those students who were willing to participate in an interview regarding their experience within the Early and Elementary Education LLC should e-mail me (first author) to schedule a meeting at a mutually agreed upon location on the Ball State University campus. This recruitment attempt gathered approximately five participants. Because of the small response rate, snowball sampling (Patton, 1990) techniques were used, meaning that participants were asked if they knew others who fit the criteria who might be willing to participate. This technique provided an additional three participants. Because it was decided that more participants would add to the depth and quality of the study, I asked for assistance from faculty members who teach in the Department of Elementary Education and work closely within the LLC. These faculty members each provided a list of approximately five names, and indicated to send a follow up e-mail to these students stating specifically that they were referred to participate through the respective faculty member. This recruitment attempt generated seven additional participants, making for a total of fifteen participants in whole.

Table 2. Participant Demographics

\begin{tabular}{|c|c|c|}
\hline \multicolumn{4}{|c|}{ Table 2. Participant Demographics } \\
\hline Name & Major & Gender \\
\hline Brianna & Elementary Ed & Female \\
\hline Drake & Elementary Ed & Male \\
\hline Sarah & Elementary Ed & Female \\
\hline Amanda & Elementary Ed & Female \\
\hline Aaron & Elementary Ed & Male \\
\hline Julie & Elementary Ed & Female \\
\hline Nathan & Elementary Ed & Female \\
\hline Ellen & Elementary Ed & Female \\
\hline Morgan & Early Childhood & Female \\
\hline Kelly & Early Childhood & Female \\
\hline Jeremy & Elementary Ed & Male \\
\hline Amber & Elementary Ed & Female \\
\hline Holly & Elementary Ed & Female \\
\hline Brittany & Elementary Ed & Female \\
\hline Rebecca & Elementary Ed & Female \\
\hline
\end{tabular}

All participants within the study at the time of data collection were sophomores or juniors who lived in the departments' LLC for a minimum of one academic-year. Most of the students were part of the departments major in elementary education. Semi-structured interviews were used. This format permitted each student to explain his or her specific thoughts and reflections thoroughly and did not constrain responses (Brophy, 2005). Of the 15 participants, 12 were female and three were male. The majority of the participants were in their sophomore year and elementary education majors (see Appendix A).

For purposes of accuracy, with participant permission, the interviews were audiotaped using a digital recorder and transcribed. Any names used on the audiotape were 
changed to pseudonyms when the tapes were transcribed, and are listed as pseudonyms within this paper. After collecting the data and converting into transcription form, I shared the data with a faculty supervisor (second author) who assisted me with data analysis. Transcripts were used to analyze the data through a phenomenoglical approach. This method of data analysis is described as "a research strategy of inquiry in which the researcher identifies the essence of human experiences about a phenomenon as described by participants” (Creswell, 2013, p. 13). While analyzing the data we identified certain codes within the data by assigning meaning to short pieces of the transcript by assigning a word or short phrase. We then used codes to generate themes. Certain themes were identified as most significant, determined by the number of participants who addressed a certain subject, combined with the amount of time this topic was discussed. In other words, codes that consistently focused on a similar topic were gathered into a certain theme. A Word document was created in which themes were listed indicating the various codes that were assigned to each theme. This process, although tedious and messy, allowed us to make meaning of the interview data that was gathered.

\section{Findings}

Many important themes consistently were reported among participants. These themes revolved around aspects of the LLC that participants saw as helpful or beneficial. Although participants were prompted during the interview to focus on both positive and negative aspects of their overall experience, responses were overwhelmingly positive. The themes within interviews of all participants consisted of comfort within the transition to college, social benefit including the development of long-term and more casual friendships, and academic benefit including better course performance and increased commitment to the field of study.

\subsection{Comfort within the College Transition}

Participants repeatedly spoke about the anxiety that accompanied the transition from high school to college and how this was quickly eased by their experience living with others who shared an academic major. Several participants spoke of the ease that was created because of this connection with those living around them and specifically indicated that this was extremely helpful and comforting especially early within their freshman experience. Sarah, for example, spoke about how she was nervous that she would not make friends quickly, and that she would not find others like her. She was particularly anxious about going to her classes, and spoke about how comforting it was to quickly meet others to attend class with her saying "knowing that I had other people who were in my major and I could go to classes with them, it really helped with the security”. Julie spoke about the transition to college by focusing on the entire first semester, and on how knowing those in her classes provided her comfort. She indicated:

You have classes with all those same people so it was nice even going in the first couple of days and thinking "Oh, they live on my floor" and recognizing them.
Because obviously you're going to be really nervous your first semester of classes. So I think that helped a lot.

Kelly spoke about how her transition to college was difficult, but was made easier by living with those in which she knew she had a common ground. She indicated:

Living with people in the same major helped me with the transition. Because I think it would have been a lot harder if I would have been living with people who I didn't have any classes with. It almost gave us something to talk about in the beginning, and then we could branch off of that.

It was apparent that nearly all the participants felt a sense of connection and security even within their first few days of their freshman experience because of their placement within in the LLC. Some participants even spoke about observations of other friends outside of the LLC within the early part of their freshman experience, and indicated they saw them struggle to connect with others in the way they could because of their specific living arrangement.

\subsection{Academic Benefits}

Although friendships in and of themselves are important to freshman students in terms of their life satisfaction, they were also often seen as connected to academic advantages by participants. Brianna spoke about how some of the friendships that she developed, although likely would not be life-long, were helpful in terms of providing confidence within her education:

I've build friendships and relationships that I will probably have throughout college. Even if it's just "hey I have a question or need help”. We don't live in the LLC anymore but we've still kept in contact. Like I have a friend who is really good in science which I'm not and I know she is there to help me. We help each other.

Amanda spoke specifically about the benefits of having an academic peer mentor that lived in the housing unit. This peer mentor was an upper-classman who was placed in the dormitory intentionally by residence life to assist students with challenges or questions that may arise. Amanda found this person very helpful academically. She stated:

Well I definitely learned a lot about what I was supposed to do. Because I came into college and was like "I have no clue what to do. I'm taking these classes but what am I doing?” And so knowing that like I had to take the Praxis and knowing about student teaching and being in the classroom... I think it was an academic advantage because I knew what was going on and that I had that person to go to for... for LLC we had an academic peer mentor and just having that person there if I needed help I think it was definitely an academic advantage.

Morgan spoke directly about how her relationship with others on the floor motivated her to be a better student, which impacted her course grades in a positive way. She said:

My first semester I got a 3.5 GPA. Which is really high for me. Because I met 2 girls on my floor just down the hall. And they were very study-oriented and very good students. And they lived right down the hall so it's like you're around each other a lot and involved in the same activities and had some of the same classes. And so we just kind of did our work together and studied together. 
One girl was very good about making notecards and we would quiz each other the day before the test. So that was really helpful and we all pretty much did really well.

Similarly, Brittany spoke about how the convenience of living near those in her classes was academically beneficial. She said:

Everyone who lived there we were all the same major so we had the same classes together. So it was a lot easier to work on like group projects or I know that was the first year I had ever used a MAC. And we were all in (in Educational Technology) class together and we had all these huge projects so a lot of us would all go into the study lounge together. So I think that was easier because it made me more motivated kind of because everyone was working on the same things as me.

It was apparent through nearly all the interviews that the relationships developed through the LLC at least had some advantage academically. It was repeatedly indicated that even those students who were not close friends felt comfortable working together or asking each other for help. Participants indicated they felt this dynamic improved their ability to be successful academically within their freshman year. This theme was focused on very little among male participants, who spoke much more about how the experience impacted them socially.

\subsection{Social Benefits}

Although the freshman year is often explored by educational and psychological researchers in terms of academic success, freshman students may have other priorities in mind, such as making durable friendships, which appeared to be more possible through the LLC. Several of the participants spoke about how important and lasting friendships were developed within even the first few days of their time in the LLC. Related to the theme of friendship, participants repeatedly spoke about the social benefits of being a part of the LLC. This appeared to be especially important to the far under-represented male students within this particular LLC. Drake spoke about the unique nature of developing friendships with other males who lived on his floor, as this LLC was particularly dominated by females. He said:

It just made it a whole lot easier to make friends with the people you lived with. Especially for us because we lived on like a half a floor last year. And there was only about 20 of us on the floor. So it made us feel really close. Because everybody knew everybody.

Nathan, another male participant, echoed Drake's sentiment indicating that he felt it was easier to develop friendships because of being placed within the LLC. He said "I thought it was especially helpful because it's really easy to make friends when you're surrounded by a bunch of guys that are doing the same thing. You have a lot of things in common already." Drake response seemed to imply that because there were few men within his major, getting to know those who were studying within similar areas was especially important. Jeremy also spoke about how living in the LLC helped him to feel connected with others within the major, and described this association as almost family-like. He indicated "I think the floor as a whole really brought us together like as a family thing."

Like the men, the women also spoke about the advantage they felt socially, however, when doing so often connected this back to their studies. Ellen spoke specifically about how academics could influence the development of friendships. She said "The academic thing kind of pushed you into other people's rooms and everything so you kind of got a... it built friendships really." Rebecca showed a similar appreciation for the social benefits of being involved in an LLC. She said:

After the first week it seemed like everyone was a familiar face already. Because I saw them in classes and not just on the floor. And then, it just gets to the point where you kind of know who is going where when or who will be in the dorm. So just walking to class in the morning you can find a group of girls to walk with or you can find someone to help with your homework at night

Erin spoke about how the friendships she made within the LLC were long lasting, and were her primary friendships at college. She said:

My friend group is still the people that I met there. And we're all the same major. So we connect on that level. That we're all doing the same thing. And I know a lot of people from our floor... like there's a lot of different small friend groups that came out of that, that are all education majors. That bonded over that I guess. That was kind of what brought us all together.

Erin's response indicates that part of her ability to connect with others within her residence hall was because of the commonality of major. Jeremy similarly spoke about the friendships he build within the LLC. He indicated there was a close relationship that, through his perspective, almost felt family-like. He indicated, "I think the floor as a whole really brought us together like as a family thing. Like we'd go play walley-ball or we got a basketball team together. Um, I don't know. The friendships and the academic side of it was nice."

Holly spoke about the importance of friendships build in the LLC in a unique way. She focused on how she believes that friendships that are developed early in college are often withstanding as compared to friendships that are developed other times:

Yeah, and even my roommate this year she's an El Ed major. And I'm living with her next year in a house. And the girl I'm also living with. Another girl is from the floor with me next year. So most of my best friends are teaching majors. Just because that's who you spend your time with. And as a freshman the friends you make are most of the time the people you stay close with.

Although participants differed in the way they spoke about friendship development within the LLC, nearly all indicated they made friendships that were more meaningful because they were with others interested in the same academic field. Even those participants who spoke primarily about how friendships within the LLC were academically beneficial appeared to feel genuinely connected with their LLC peers. Most participants mentioned that even after their time in the LLC concluded there was still close contact between students who had previously resided within it.

\section{Discussion}

Numerous studies focusing on the effect of LLCs have indicated that students often very quickly feel more connected to their peers and even to their academic field 
as a result of being housed in a LLC. This finding was replicated through the experiences of participants within this study, and is important especially in light of the recent attention given to the dangers of particularly the first few weeks and even months of the college transition (New, 2014). Research such as that done by Brower (2008) consistently demonstrates that students who are more aware of their residential peers are less likely to engage in high-risk behaviors influenced by peer pressure. The academic benefits reported by participants are also supported by the vast body of scholarly literature as well as the Ball State University LLC Academic Outcomes Report (Table 2) which indicates a higher level of student performance and retention among those participating in an LLC at Ball State University. It appeared through this study that the development of this major-specific LLC was particularly beneficial for those students involved for a variety of reasons. All participants spoke emphatically about how they felt they had benefitted from this living arrangement. Each of the 15 participants indicated that they were glad they were part of the LLC, and that they would recommend this to an incoming student within the major.

It is possible that some of the participant's experiences within this study were influenced by various factors such as gender. The female participants spoke much more about how the LLC experience benefitted them academically, while the male participants spoke more about how the experience befitted them socially. Upon exploration of this phenomenon in previous research, it was found that the findings of this study could be supported by previous literature such as that conducted by Yongyi, Arboleda, Shelley, \& Whalen (2004) which indicates that academically successful women tend to spend more time and focus within their residence hall environment on academic pursuits. Similarly, Eshbaugh (2008) found that men within residence halls are more likely to report loneliness. This might be important as this can be combatted through social support, which may be impacted positively through a residence hall affiliation such as a major-specific LLC. It is logical that men especially within a major in which they are underrepresented may feel especially pleased to develop friendships with other men with similar interests and goals. It is possible that these men experienced little contact with other males who shared their interest before being connected through the LLC. Because the women within the LLC likely had likely experienced a high level of contact with other women interested in early or elementary education even before their transition to college, it is understandable that the social benefit of living in an LLC may be less significant to them.

It is important to mention that the findings presented within this study could have been influenced by a number of factors. For example, LLCs can be arranged very differently across or even within institutions. Some may be organized with much intention, or very consistently, while others may be more sporadic. Some may have high faculty involvement, or may intentionally place students in the LLC in the same class sections, while others may not. Even in those instances in which an LLC was created with carefulness, it is possible that the characteristics of the students themselves may be very important to the success of the structure over-all. For example, students pursuing a highly social field, such as education, may wish to be connected with others much more than those within other fields. Although the participants within this study spoke about their experience in a positive way, it would be important to compare these experiences to other students at the university or within the dormitory who were not part of the Department of Elementary Education's majors. Further research should examine how other students within similar fields of education experienced their freshman residence involvement if they were not part of an organized LLC.

\section{References}

[1] Brophy, J.E. (2005). Goal theorists should move on from performance goals. Educational Psychologist, 40, 167-176.

[2] Brower, A. M. (2008). More like a home than a hotel: The impact of living-learning programs on college high-risk drinking. Journal of College \& University Student Housing, 35 (1), 32-49.

[3] Creswell, J. W. (2009). Research design: Qualitative, quantitative, and mixed methods approaches. Los Angeles: Sage.

[4] Eshbaugh, E.M. (2008). Brief Report: Gender, Social Support, and Loneliness among Residence Hall Students. Journal of College \& University Student Housing, 35 (2), 24-33.

[5] Foste, Z., Edwards, K., \& Davis, T. (2012). Trial and error: Negotiating manhood and struggling to discover true self. Journal of College \& University Student Housing, 8/39 (2/1), 124-139.

[6] Frazier, W., \& Eighmy, M. (2012). Themed residential learning communities: The importance of purposeful faculty and staff involvement and student engagement. Journal of College \& University Student Housing, 38/39, 10-31.

[7] Garrett, M. D., \& Zabriskie, M. S. (2004). The influence of livinglearning program participation on student-faculty interaction. Journal of College \& University Student Housing, 33, 38-44.

[8] Henderickson, J.M., Vander Busard, A., Rodgers, D., \& Scheideckers, B. (2013). Students with intellectual disabilities: How are they faring? Journal of College \& University Student Housing, 39/40, 186-199.

[9] Inkelas, K., Daver, Z. E., Vogt, K. E., \& Leonard, J. (2007) Living-learning programs and first-generation college students' academic and social transition to college. Research in Higher Education, 48, 403-434.

[10] Jessup-Anger, J.E., Johnson, B.N., \& Wawrzynski, M.R. (2012). Exploring living-learning communities as a venue for men's identity construction. Journal of College \& University Student Housing, 38/39, 162-175.

[11] Johnson, J. L., \& Romanoff, S. J. (1999). Higher education residential learning communities: What are the implications for student success? College Student Journal, 33, 385.

[12] New, J. (2014). Lives cut short. Inside Higher Ed. Retrieved from: https://www.insidehighered.com/news/2014/09/19/freshmandeaths-show-risks-transitioning-college-life

[13] Patton, M.Q. (1990). Qualitative evaluation and research methods. London: Sage.

[14] Pitt, R.N. \& Borland, E. (2008). Bachelorhood and Men's Attitudes about Gender Roles. Journal of Men's Studies, 16 (2), 140-158.

[15] Rohli, R. V., \& Rogge, R. A. (2012). An empirical study of the potential for geography in university living-learning communities in the United States. Journal of Geography in Higher Education, 36 (1), 81-95.

[16] Shushok, F., \& Sriram, R. (2009). Exploring the effect of a residential academic affairs-student affairs partnership: The first year of an engineering and computer science living-learning center. Journal of College \& University Student Housing, 36 (2), 68-81.

[17] Stassen, M. A. (2003). Student outcomes: The impact of varying living-learning community models. Research in Higher Education, 44 (5), 581.

[18] Szelényi, K., Denson, N., \& Inkelas, K. (2013). Women in STEM majors and professional outcome expectations: The role of livinglearning programs and other college environments. Research in Higher Education, 54 (8), 851-873.

[19] Yongyi, W., Arboleda, A., Shelley II, M. C., \& Whalen, D. F. (2004). The influence of residence hall community on academic success of male and female undergraduate students. Journal of College \& University Student Housing, 33, 16-22. 